\title{
POTENTIAL EFFECT OF PHARMACOTHERAPY ON SYMPATHETIC AROUSAL IN AUTISM \\ Bujnakova ${ }^{1,2}$, Ondrejka ${ }^{4}$, Mestanik $\mathrm{M}^{1}$, Fleskova $\mathrm{D}^{4}$, Sekaninova $\mathrm{N}^{1,2}$, FARSKY I ${ }^{3,4}$, TONHAJZEROVA I ${ }^{1,2}$
}

${ }^{1}$ Biomedical Center Martin, Jessenius Faculty of Medicine in Martin, Comenius University in Bratislava, Martin, Slovakia, ${ }^{2}$ Department of Physiology, Jessenius Faculty of Medicine in Martin, Comenius University in Bratislava, Martin, Slovakia, ${ }^{3}$ Department of Nursing, Jessenius Faculty of Medicine in Martin, Comenius University in Bratislava, Martin, Slovakia, ${ }^{4}$ Clinic of Psychiatry, Jessenius Faculty of Medicine in Martin, Comenius University in Bratislava, University Hospital Martin, Slovakia

\begin{abstract}
Background: Autism spectrum disorder (ASD) is a serious neurodevelopmental disorder associated with autonomic nervous system (ANS) abnormalities. Moreover, at least 50\% of children with ASD suffer from other comorbid diseases such as anxiety, depression, and attention deficit hyperactivity disorder (ADHD) associated with receiving psychotropic medication. From this context we aimed to evaluate changes in sympathetic arousal using analysis of electrodermal activity (EDA) as an index of sympathetic cholinergic activity in treated and non-treated autistic children under resting conditions.

Methods: We examined 23 children with ASD and 14 healthy age- and gender- matched children at the age of 7-15 years. The ASD patients were divided into ASD non-treated group $(n=12)$ and ASD treated group $(n=11)$. The EDA was continuously monitored during resting phase in a supine position. The EDA amplitude $(\mu \mathrm{S})$ was computed as an average of $5 \mathrm{~min}$ baseline period.

Results: We found significantly lower EDA in ASD non-treated subgroup compared to controls indicating subtle abnormalities in the regulation of the sympathetic nervous system. Although no significant differences were found between the ASD treated and non-treated subgroups the ASD treated group showed comparable sympathetic activity relative to controls indicating a potential ameliorated treatment effect on sympathetic arousal in ASD.

Conclusions: These findings could help to determine differences in sympathetic arousal in treated and non-treated children with ASD, which is important for assessment of autism-linked cardiovascular risk depending on pharmacotherapy.
\end{abstract}

Key words: autism spectrum disorder - comorbidity - pharmacotherapy - sympathetic nervous system - electrodermal activity

\section{INTRODUCTION}

The autonomic nervous system (ANS) is responsible for maintaining homeostasis, adaptability, and physiological flexibility of the organism. Physiologically, both of the sympathetic and parasympathetic systems work at dynamic balance at rest as well as in response to stress. Dysfunction of this system plays a crucial role in the pathogenesis of many diseases contributing to cognitive, behavioral, and affective abnormalities in children with autism (1).

Address for correspondence:

Iveta Bujnakova, MD., Department of Physiology and Biomedical Center Martin, Jessenius Faculty of Medicine in Martin, Comenius University in Bratislava, Mala Hora 4C 03601 Martin, Slovakia; Phone: +421 432633678 ;

e-mail: iveta.bujnakova@uniba.sk 
Autism spectrum disorder (ASD) is a complex neurodevelopmental disorder characterized by persistent deficits in social communication and interaction and by the presence of restricted interests and repetitive behaviors. These deficits are manifested in early childhood and lead to impaired ability to form normal human relations. However, children with ASD are characterized not only by their core deficits but they also suffer from many comorbid diseases such as intellectual developmental disorder, learning disability, attention deficit/hyperactivity disorder (ADHD), anxiety, obsessive-compulsive disorder (OCD), or behavioral problems $(2,3)$. According to the current DSM-5 criteria (Diagnostic and statistical manual of mental disorders, Fifth Edition) about $70 \%$ of individuals with ASD may have one comorbid mental disorder and $40 \%$ may have two or more comorbid mental disorders (4). In addition, previous studies found that $35 \%$ to $56 \%$ of children with ASD had used at least one psychotropic medication and $20 \%$ of them were prescribed more than three medications during the year $(5,6)$.

Many children with autism show symptoms related to autonomic nervous system (ANS) functioning abnormalities. Recent studies have found inconsistent results including elevated heart rate $(7-10)$, reduced parasympathetic tone $(8,10-12)$, or larger pupil size $(13,14)$. In addition, atypical ANS responses to various stimuli were observed in ASD children, such as attenuated heart rate response to social anxiety task (15), blunted both heart rate and salivary cortisol response to social stress $(16,17)$, or increased cardiac vagal tone in response to mental arithmetic test (18). Regarding sympathetic activity quantified by electrodermal activity (EDA) the existing findings in ASD are mixed, such as unaltered basal EDA $(16,19)$, increased EDA $(9,20)$, decreased basal EDA $(21)$, or decreased basal EDA associated with reduced reactivity to the anxiety tasks (22). Although at least $50 \%$ of ASD persons receive psychotropic medications there is a lack of literature comparing the effect of treatment on the studied autonomic parameters. For example, Bink et al. (23) investigated the effects of stimulant medications on cardiac activity during baseline in ASD and ADHD groups using the heart rate variability analysis. They found higher LF/HF ratio (as an index of sympathovagal balance) at rest and decreased $\mathrm{LF} / \mathrm{HF}$ reactivity to task performance in treated ASD and ADHD group compared to non-treated group. Similarly, a significant medication effect was observed on heart rate and HRV parameters in ASD children compared to controls (24). In contrast, Schoen et al. (25) found no medication effect on EDA. However, more than half of participants in no-medication group showed low EDA arousal.

Thus, in terms of the potential role of medication effect on autonomic parameters, we aimed to compare resting sympathetic activity using electrodermal activity in the treated and non-treated autistic children. To our knowledge, this association has not been sufficiently investigated in ASD children.

\section{METHODS}

The study was approved by the Ethics Committee of the Jessenius Faculty of Medicine in Martin, Comenius University in Bratislava, Slovakia. All procedures performed in our study were in accordance with the Declaration of Helsinki of the World Medical Association. All children and their guardians were carefully informed about the study protocol and informed written consent was obtained prior to examination.

We examined 23 children with ASD at the age of $7-15$ years ( 3 females, average age: $11.1 \pm 0.5$ years, BMI: $18.8 \pm 0.6 \mathrm{~kg} / \mathrm{m}^{2}$ ) and 14 age- and gender- matched healthy children ( 3 females, average age: $10.7 \pm 0.6$ years, BMI: $18.3 \pm 0.7 \mathrm{~kg} / \mathrm{m}^{2}$ ).

The ASD patients were recruited from Clinic of Psychiatry at the University Hospital in Martin. Inclusion criteria used for enrolling children for the ASD group were: primary ASD diagnosis, IQ above 70, ability to perform the study, and body mass index (BMI) (in order to exclude obesity, overweight, or underweight). The BMI range was strictly respected according to extended International Obesity Task Force (IOTF) with ASD group range 15.68 
to $23.30 \mathrm{~kg} / \mathrm{m}^{2}$ and control group range 15.50 to $23.00 \mathrm{~kg} / \mathrm{m}^{2}$, corresponding to percentile range from 25. to 75. percentile (26). The diagnosis of ASD, severity level 1 in social communication and restricted repetitive behaviors, was assessed by a child and adolescent psychiatrist according to the diagnostic criteria of DSM-5 (4). Furthermore, the presence of other psychiatric symptoms and comorbid mental disorders in ASD group was confirmed by a supervised qualified specialist in child and adolescent psychiatry according to DSM-5 diagnostic criteria prior to examination. Consequently, the ASD patients were divided into two subgroups: those without any treatment - ASD non-treated group $(n=12,1$ female, average age: $10.8 \pm 0.7$ years) and those with comorbidities and pharmacological treatment - ASD treated group ( $\mathrm{n}=11,2$ females, $11.4 \pm 0.9$ years). Most of autistic children in treated group $(n=8)$ suffered from comorbid ADHD with taking ADHD-linked treatment (methylphenidate $-18 \mathrm{mg} /$ day, atomoxetine $-1.2 \mathrm{mg} / \mathrm{kg} /$ day). Other medications include antidepressant therapy - selective serotonin reuptake inhibitors (SSRIs: sertraline $-50 \mathrm{mg} /$ day, fluoxetine $-20 \mathrm{mg} /$ day, fluvoxamine - $100 \mathrm{mg} /$ day) and antiepileptic treatment (valproate $-30 \mathrm{mg} / \mathrm{kg} /$ day). It should be noted that there is no specific treatment for core symptoms of autism spectrum disorder (27). The psychopharmacologic drugs used in ASD treated group were primarily indicated to comorbidities treatment, especially to ADHD-like symptoms. All drugs were orally administered with good tolerability. Moreover, medications were administered last time 24 hour before the examination to avoid the acute effect of medication. However, we take into consideration that longer wash out period of antidepressants (sertraline and fluvoxamine with 10-14 days, fluoxetine with 5 weeks) could potentially affect autonomic activity (28-30). The intellectual functioning was conducted by a licensed practitioner - a clinical psychologist using Wechsler Intelligence Scale for Children (WISC III). Full scale IQ scores for ASD were above 80. Control participants were healthy volunteers not suffering from any mental or neurodevelopmental disorders, neither taking any medication. Exclusion criteria for both ASD and control groups include acute infection, cardiovascular, endocrine and respiratory disease, and other conditions potentially influencing ANS (obesity, overweight, underweight, alcohol, or drug abuse). Basic groups' characteristics are presented in Table 1.

Tab. 1 The characteristics of studied groups

\begin{tabular}{|l|c|c|c|}
\hline & Controls $(\mathrm{n}=14)$ & ASD non-treated $(\mathrm{n}=12)$ & ASD treated (n = 11) \\
\hline Age (years) & $10.7 \pm 0.6$ & $10.8 \pm 0.7$ & $11.4 \pm 0.9$ \\
\hline BMI $\left(\mathrm{kg} / \mathrm{m}^{2}\right)$ & $18.3 \pm 0.7$ & $18.7 \pm 1.0$ & $18.8 \pm 0.8$ \\
\hline Comorbidities & - & - & $\begin{array}{c}\text { ADHD (8), anxiety disorder (2), } \\
\text { disruptive disorders (1) }\end{array}$ \\
\hline Medication & - & - & $\begin{array}{c}\text { atomoxetine (3), methylphenidate } \\
\text { (3), valproate (3), sertraline (2), } \\
\text { lluoxetine (1), fluvoxamine (1) }\end{array}$ \\
\hline
\end{tabular}

ASD - autism spectrum disorder, BMI - body mass index, ADHD - attention deficit hyperactivity disorder

All children were examined in a quiet room under standard conditions in the morning between 8:00 and 12:00 am. After initial anthropometric examination using InBody 120 (Biospace Co., Ltd., Korea) the EDA sensors were placed on the child's fingers. Then they were instructed to lie down and remain for 5 min without speaking and movement to sta- 
bilize the ANS. The EDA signal was continuously monitored using the device FlexComp Infiniti (Thought Technology Ltd., Canada) by applying a constant electrical voltage between two electrodes (dry $\mathrm{Ag} / \mathrm{AgCl}$ electrodes) placed at the medial phalanges of two fingers of non-dominant hand. This allows measurement of skin conductance level, which represents changes in sweat gland activity due to stress or emotional excitement. Artifacts resulting from children's body movements were distinguished on the output trace and excluded from the analysis. Mean EDA level ( $\mu \mathrm{S})$ was computed as an average of baseline period lasted for 5 min.

The statistical analysis was performed using the statistical software MYSTAT 12 for Windows (SSI, Richmond, CA, USA). The Kruskal Wallis nonparametric test was used for assessment of differences because of non-gaussian distribution of the data ascertained by Shapiro-Wilk normality test. A value of $\mathrm{p}<0.05$ was considered statistically significant. Data were expressed as the mean \pm SEM.

\section{RESULTS}

The statistical analysis revealed that the ASD non-treated group had a significantly lower baseline EDA compared to controls $(0.65 \pm 0.15 \mu \mathrm{S}$ vs. $1.40 \pm 0.16 \mu \mathrm{S}, \mathrm{p}=0.005)$. Moreover, the EDA displayed a tendency towards a significant difference between the ASD non-treated and the ASD treated groups $(0.65 \pm 0.15 \mu \mathrm{S}$ vs. $1.05 \pm 0.18 \mu \mathrm{S}, \mathrm{p}=0.074)$. No significant differences were found between the ASD treated group and controls (Fig.1).

Fig. 1 Mean EDA dur-

ing rest in

control group and non-treated and treated children suffering from autism spectrum disorders (ASD). ${ }^{*} \mathrm{p}<0.05$

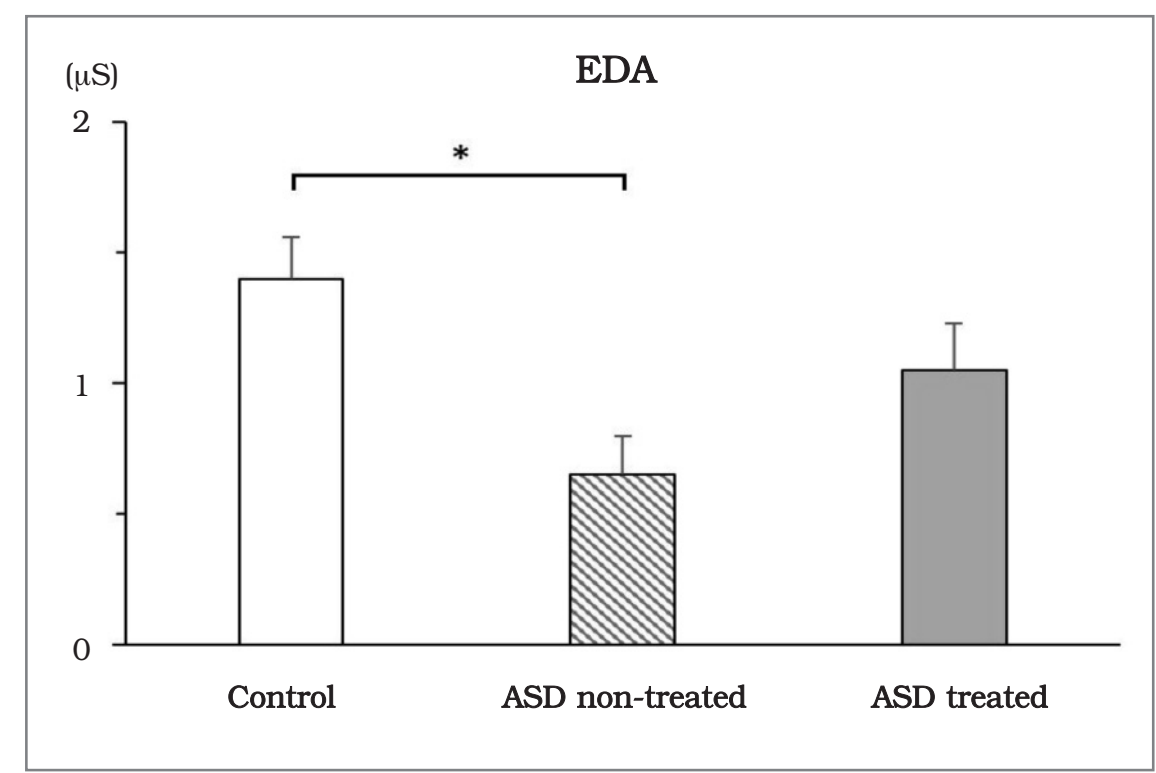

\section{DISCUSSION}

In this study we assessed resting sympathetic activity in groups of treated and non-treated autistic children using electrodermal activity. The major finding is that sympathetic activity indexed by EDA was lower in the non-treated group compared to controls, while the treated ASD group showed comparable sympathetic activity relative to controls. 
Autism spectrum disorder (ASD) represents a neurodevelopmental disorder that is associated with autonomic dysregulation. Electrodermal activity (EDA) is characterized as a non-invasive psychophysiological index of changes in sympathetic neuronal activity regulating the activity of eccrine sweat glands (31). Skin conductance level reflects slow spontaneous electrical fluctuations of sweat gland activity indicating the general degree of arousal. Although our previous study revealed reduced resting EDA in ASD group (21) the neurophysiological mechanisms leading to atypical EDA and other autonomic parameters related to ASD are still unexplored. Central control of EDA has an excitatory and inhibitory effects on the sympathetic nervous system originate in various structures of CNS. Boucsein (32) has described two main pathways influencing sweat production: limbic-hypothalamic pathway related to emotions and thermoregulation and premotor-basal ganglia pathway related to preparation for motor movements. Hypothalamus, as a main integrative structure of ANS control system, is modified especially by amygdala (excitation) and by the hippocampus (inhibition). Moreover, the elicitation of EDA is modified by regulatory effects of reticular formation in the brainstem $(32,33)$. In this context, structures as prefrontal cortex, anterior cingulate cortex, and amygdala, involved in regulation of EDA, are considered as abnormal in ASD children (34-37). In particular, the pathological changes of amygdala are associated with difficulties in interpreting gaze information, seizure activities, and failure of recognition of social emotions (38). Recent study investigating amygdalo-cortical connectivity by fMRI in adolescents with ASD confirmed reduced cortical connectivity of amygdaloid input subregions with the prefrontal, parietal, and occipital cortices (39). Moreover, Courchesne and Pierce (40) clarified that connectivity within frontal lobe in ASD is excessive and disorganized, whereas connectivity between frontal cortex and other systems is reduced. We assume that differences in neuroanatomy and functional characteristics in these regions may profoundly affect sympathetic function in ASD children quantified by EDA, as we found in the previous study (21). The low arousal theory explains that people with externalizing disorders, e.g. ADHD or antisocial personality disorder, seek selfstimulation by excessive activity in order to activate their state of abnormally low arousal. This low arousal results in the inability or difficulty to sustain attention or to control compulsive hyperactive behavior (41). Previous studies reported that about half of ASD population also meets diagnostic criteria for ADHD diagnosis characterized by core symptoms hyperactivity, inattention, and impulsivity (42-44). With regard to specific ADHD treatment, methylphenidate (MPH) is a central stimulant inhibiting the reuptake of dopamine and norepinephrine into the presynaptic neuron and increasing the release of these monoamines into the extraneuronal space in the prefrontal cortex. Specifically, the MPH could increase mean heart rate, mean blood pressure, or skin conductance level indicating increased sympathetic activity (45-46). Despite the fact that increased noradrenergic neurotransmission in the prefrontal cortex - due to atomoxetine as a specific noradrenaline reuptake inhibitor - could elevate blood pressure and heart rate $(47,48)$, the cardiovascular effects of atomoxetine were minimal in ADHD patients $(49,50)$. However, to best of our knowledge, the effect of atomoxetine on skin conductance is still unknown.

Moreover, regarding the antidepressant therapy used in our study, the previous longitudinal study showed a different medications effect on ANS depending on type of antidepressants: while tricyclic antidepressants (TCA) increased cardiac sympathetic activity evaluated by pre-ejection period (51), recent review referred to nonsignificant effect of the selective serotonin reuptake inhibitors (SSRI) on autonomic functioning (28). In this study the sympathetic arousal indexed by EDA was lower in the ASD non-treated group whereas the ASD treated group showed comparable sympathetic activity relative to controls. Further, the treated ASD children displayed a tendency to significant higher EDA compared to the non-treated ASD children. Thus, we could hypothesize that the EDA trend to rise in the ASD treated group might rather reflect the effect of central stimulants (methylphenidate, atomoxetine) than the antidepressants due to a potentially greater influence of noradrenergic effect on sympathetic arousal in autistic children. 
Nevertheless, the effect of comorbid disorders should be taken into consideration. Recent studies revealed cardiac-linked sympathetic activity indexed by linear as well as nonlinear indices of heart rate variability analysis ( $\mathrm{LF} / \mathrm{HF}, \mathrm{OV} \%)$ in untreated children suffering from pure ADHD (52-54). We could speculate that our results of increased EDA in the treated ASD children might also reflect a potential effect of comorbid disorders associated with ASD. Thus, it is questionable whether our findings are related to alone effect of pharmacotherapy or they could indicate clinically potential asymptomatic symptoms of autism-linked comorbid disorders. In terms of a more comprehensive assessment of autonomic regulation there is a need to correlate our findings with other autonomic parameter, such as heart rate variability (HRV). Other limitation of this study is a small and variable ASD treated group, with comorbidities potentially influencing the autonomic activity. However, this statement requires future research based on larger and more homogenous samples of ASD-linked treated subgroups.

\section{CONCLUSION}

This study revealed discrete abnormalities in sympathetic cholinergic regulation indexed by EDA in treated and non-treated autistic children. We assume that the EDA evaluation could contribute to illuminate the effect of pharmacotherapy on sympathetic functioning in autistic children, which is important for assessment of autism-linked regulatory abnormalities associated with cardiovascular risk.

\section{REFERENCES}

1) Benevides TW, Lane SJ. A review of cardiac autonomic measures: consideration for examination of physiological response in children with autism spectrum disorder. J Autism Dev Disord 2015; 45(2): 560-75.

2) Leyfer OT, Folstein SE, Bacalman S, Davis NO, Dinh E, Morgan J et al. Comorbid psychiatric disorders in children with autism: interview development and rates of disorders. J Autism Dev Disord 2006; 36(7): 849-61.

3) Murray ML, Hsia Y, Glaser K, Simonoff E, Murphy DG, Asherson PJ et al. Pharmacological treatments prescribed to people with autism spectrum disorder (ASD) in primary health care. Psychopharmacology (Berl) 2014; 231(6): 1011-21.

4) American Psychiatric Association. Diagnostic and statistical manual of mental disorders. 5th ed. Washington (DC): American Psychiatric Publisher; 2013.

5) Mandell DS, Morales KH, Marcus SC, Stahmer AC, Doshi J, Polsky DE. Psychotropic medication use among Medicaid-enrolled children with autism spectrum disorders. Pediatrics 2008; 121(3): e441-8.

6) Rosenberg RE, Mandell DS, Farmer JE, Law JK, Marvin AR, Law PA. Psychotropic medication use among children with autism spectrum disorders enrolled in a national registry, 2007-2008. J Autism Dev Disord 2010; 40(3): 342-51.

7) Ming X, Julu PO, Brimacombe M, Connor S, Daniels ML. Reduced cardiac parasympathetic activity in children with autism. Brain Dev 2005; 27(7): 509-16.

8) Bal E, Harden E, Lamb D, Van Hecke AV, Denver JW, Porges SW. Emotion recognition in children with autism spectrum disorders: relations to eye gaze and autonomic state. J Autism Dev Disord 2010; 40(3): 358-70.

9) Kushki A, Drumm E, Pla Mobarak M, Tanel N, Dupuis A, Chau T et al. Investigating the autonomic nervous system response to anxiety in children with autism spectrum disorders. PLoS One 2013; 8(4): e59730.

10) Porges SW, Macellaio M, Stanfill SD, Mccue K, Lewis GF, Harden ER et al. Respiratory sinus arrhythmia and auditory processing in autism: modifiable deficits of an integrated social engagement system? Int J Psychophysiol 2013; 88(3): 261-70. 
11) Patriquin MA, Scarpa A, Friedman BH, Porges SW. Respiratory sinus arrhythmia: a marker for positive social functioning and receptive language skills in children with autism spectrum disorders. Dev Psychobiol 2013; 55(2): 101-12.

12) Neuhaus E, Bernier R, Beauchaine TP. Brief report: social skills, internalizing and externalizing symptoms, and respiratory sinus arrhythmia in autism. J Autism Dev Disord 2014; 44(3): 730-7.

13) Anderson CJ, Colombo J, Unruh KE. Pupil and salivary indicators of autonomic dysfunction in autism spectrum disorder. Dev Psychobiol 2013; 55(5): 465-82.

14) Wagner JB, Luyster RJ, Tager-Flusberg H, Nelson CA. Greater pupil size in response to emotional faces as an early marker of social-communicative difficulties in infants at high risk for autism. Infancy 2016; 21(5): 560-81.

15) Kushki A, Brain J, Dupuis A, Anagnostou E. Functional autonomic nervous system profile in children with autism spectrum disorder. Mol Autism 2014; 5: 39.

16) Levine TP, Sheinkopf SJ, Pescosolido M, Rodino A, Elia G, Lester B. Physiologic arousal to social stress in children with autism spectrum disorders: a pilot study. Res Autism Spectr Disord 2012; 6(1): 177-83.

17) Hollocks MJ, Howlin P, Papadopoulos AS, Khondoker M, Simonoff E. Differences in HPA-axis and heart rate responsiveness to psychosocial stress in children with autism spectrum disorders with and without co-morbid anxiety. Psychoneuroendocrinology 2014; 46: 32-45.

18) Toichi M, Kamio Y. Paradoxical autonomic response to mental tasks in autism. J Autism Dev Disord 2003; 33(4): 417-26.

19) Legiša J, Messinger DS, Kermol E, Marlier L. Emotional responses to odors in children with highfunctioning autism: autonomic arousal, facial behavior and self-report. J Autism Dev Disord 2013; 43(4): 869-79.

20) O'Haire ME, McKenzie SJ, Beck AM, Slaughter V. Animals may act as social buffers: skin conductance arousal in children with autism spectrum disorder in a social context. Dev Psychobiol 2015; 57(5): 584-95.

21) Bujnakova I, Ondrejka I, Mestanik M, Visnovcova Z, Mestanikova A, Hrtanek I et al. Autism spectrum disorder is associated with autonomic underarousal. Physiol Res 2016; 65(Suppl 5): S673-S682.

22) Panju S, Brian J, Dupuis A, Anagnostou E, Kushki A. Atypical sympathetic arousal in children with autism spectrum disorder and its association with anxiety symptomatology. Mol Autism 2015; 6:64.

23) Bink M, Popma A, Bongers IL, van Boxtel GJ, Denissen A, van Nieuwenhuizen Ch. Cardiac reactivity and stimulant use in adolescents with autism spectrum disorders with comorbid ADHD versus ADHD. J Autism Dev Disord 2015; 45(2): 481-94.

24) Daluwatte CH, Miles JH, Christ SE, Beversdorf DQ, Takahashi TN, Yao G. Atypical pupillary light reflex and heart rate variability in children with autism spectrum disorder. J Autism Dev Disord 2013; 43(8): 1910-25.

25) Schoen SA, Miller LJ, Brett-Green B, Hepburn SL. Psychophysiology of children with autism spectrum disorder. Res Autism Spectr Disord 2008; 2(3): 417-29.

26) Cole TJ, Lobstein T. Extended international (IOTF) body mass index cut-offs for thinness, overweight and obesity. Pediatr Obes 2012; 7(4): 284-94.

27) Ji N, Findling RL. An update on pharmacotherapy for autism spectrum disorder in children and adolescents. Curr Opin Psychiatry 2015; 28(2): 91-101.

28) Licht CM, Penninx BW, de Geus EJ. Effects of antidepressants, but not psychopathology, on cardiac sympathetic control: a longitudinal study. Neuropsychopharmacology 2012; 37(11): 2487-95.

29) Breitbart WS, Alici Y. Psychosocial palliative care. Oxford University Press; 2014.

30) Keks N, Hope J, Keogh S. Switching and stopping antidepressants. Australian Prescriber 2016; 39(3): 76-83.

31) Dawson M, Schell A, Filion D. The electrodermal system. In: Cacioppo JT, Tassinary LG, Berntson GG, editors. Handbook of psychophysiology. New York: Cambridge University Press; 2000.

32) Boucsein W. Electrodermal Activity. New York: Springer; 2012.

33) Sequeira H, Hot P, Silvert L, Delplanque S. Electrical autonomic correlates of emotion. Int J Psychophysiol 2009; 71(1): 50-6.

34) Brambilla P, Hardan A, di Nemi SU, Perez J, Soares JC, Barale F. Brain anatomy and development in autism: review of structural MRI studies. Brain Res Bull 2003; 61(6): 557-69. 
35) Amaral DG, Schumann CM, Nordahl CW. Neuroanatomy of autism. Trends Neurosci 2008; 31(3): 137-45.

36) Schumann CM, Barnes CC, Lord C, Courchesne E. Amygdala enlargement in toddlers with autism related to severity of social and communication impairments. Biol Psychiatry 2009; 66(10): 942-9.

37) Stoner R, Chow ML, Boyle MP, Sunkin SM, Mouton PR, Roy S et al. Patches of disorganization in the neocortex of children with autism. N Engl J Med 2014; 370(13): 1209-19.

38) Baron-Cohen S, Ring HA, Bullmore ET, Wheelwright S, Ashwin C, Williams SCR. The amygdala theory of autism. Neurosci Biobehav Rev 2000; 24(3): 355-64.

39) Rausch A, Zhang W, Haak KV, Mennes M, Hermans EJ, van Oort E et al. Altered functional connectivity of the amygdaloid input nuclei in adolescents and young adults with autism spectrum disorder: a resting state fMRI study. Mol Autism 2016; 7: 13.

40) Courchesne E, Pierce K. Why the frontal cortex in autism might be talking only to itself: local overconnectivity but long-distance disconnection. Curr Opin Neurobiol 2005; 15(2): 225-30.

41) Sikström S, Söderlund G. Stimulus-dependent dopamine release in attention-deficit/hyperactivity disorder. Psychol Rev 2007; 114(4): 1047-75.

42) Mukaddes NM, Hergüner S, Tanidir C: Psychiatric disorders in individuals with high- functioning autism and Asperger's disorder: similarities and differences. World J Biol Psychiatry 2010; 11(8): 964-71.

43) Murray MJ. Attention-deficit/hyperactivity disorder in the context of autism spectrum disorders. Curr Psychiatry Rep 2010; 12(5): 382-8.

44) Romero M, Aguilar JM, Del Rey-Mejías A, Mayoral F, Rapado M, Peciña M et al. Psychiatric comorbidities in autism spectrum disorder: A comparative study between DSM-IV-TR and DSM-5 diagnosis. Int J Clin Health Psychol 2016; 16(3): 266-75.

45) Lawrence CA, Barry RJ, Clarke AR, Johnstone SJ, Mccarthy R, Selikowitz M et al. Methylphenidate effects in attention deficit/hyperactivity disorder: electrodermal and ERP measures during a continuous performance task. Psychopharmacology (Berl) 2005; 183(1): 81-91.

46) Awudu GA, Besag FM. Cardiovascular effects of methylphenidate, amphetamines and atomoxetine in the treatment of attention-deficit hyperactivity disorder: an update. Drug Saf 2014; 37(9): 661-76.

47) Kasi PM, Mounzer R, Gleeson GH. Cardiovascular side effects of atomoxetine and its interactions with inhibitors of the cytochrome p450 system. Case Rep Med 2011; 2011: 952584.

48) Ding YS, Naganawa M, Gallezot JD, Nabulsi N, Lin SF, Ropchan J et al. Clinical doses of atomoxetine significantly occupy both norepinephrine and serotonin transports: Implications on treatment of depression and ADHD. Neuroimage 2014; 86: 164-71.

49) Wernicke JF, Faries D, Girod D, Brown J, Gao H, Kelsey D et al. Cardiovascular effects of atomoxetine in children, adolescents, and adults. Drug Saf 2003; 26(10): 729-40.

50) Garnock-Jones KP, Keating GM. Atomoxetine: a review of its use in attention-deficit hyperactivity disorder in children and adolescents. Paediatr Drugs 2009; 11(3): 203-26.

51) Alvares GA, Quintana DS, Hickie IB, Guastella AJ. Autonomic nervous system dysfunction in psychiatric disorders and the impact of psychotropic medications: a systematic review and metaanalysis. J Psychiatry Neurosci 2016; 41(2): 89-104.

52) Tonhajzerova I, Ondrejka I, Adamik P, Hruby R, Javorka M, Trunkvalterova $Z$ et al. Changes in the cardiac autonomic regulation in children with attention deficit hyperactivity disorder (ADHD). Indian J Med Res 2009; 130(1): 44-50.

52) Tonhajzerova I, Farsky I, Mestanik M, Visnovcova Z, Mestanikova A, Hrtanek I et al. Symbolic dynamics of heart rate variability - a promising tool to investigate cardiac sympathovagal control in attention deficit/hyperactivity disorder (ADHD)? Can J Physiol Pharmacol 2016; 94(6): 579-87.

54) Griffiths KR, Quintana DS, Hermens DF, Spooner C, Tsang TW, Clarke S et al. Sustained attention and heart rate variability in children and adolescents with ADHD. Biol Psychol 2017; 124: 11-20.

Acknowledgements: This work was supported by VEGA 1/0044/18 and the project „Biomedical Center Martin“ ITMS code: 26220220187, co-financed from EU sources.

Received: January, 18, 2018

Accepted: January, 23, 2018 